Subscriber access provided by King Abdullah University of Science and Technology Library

Article

\title{
Electropolymerized Star-Shaped Benzotrithiophenes Yield \#- Conjugated Hierarchical Networks with High Areal Capacitance
}

Andreas Ringk, Adrien Lignie, Yuanfang Hou, Husam N. Alshareef, and Pierre M. Beaujuge

ACS Appl. Mater. Interfaces, Just Accepted Manuscript • DOI: 10.1021/acsami.5b09962 • Publication Date (Web): 30 Mar 2016

Downloaded from http://pubs.acs.org on April 5, 2016

\section{Just Accepted}

"Just Accepted" manuscripts have been peer-reviewed and accepted for publication. They are posted online prior to technical editing, formatting for publication and author proofing. The American Chemical Society provides "Just Accepted" as a free service to the research community to expedite the dissemination of scientific material as soon as possible after acceptance. "Just Accepted" manuscripts appear in full in PDF format accompanied by an HTML abstract. "Just Accepted" manuscripts have been fully peer reviewed, but should not be considered the official version of record. They are accessible to all readers and citable by the Digital Object Identifier (DOI®). "Just Accepted" is an optional service offered to authors. Therefore, the "Just Accepted" Web site may not include all articles that will be published in the journal. After a manuscript is technically edited and formatted, it will be removed from the "Just Accepted" Web site and published as an ASAP article. Note that technical editing may introduce minor changes to the manuscript text and/or graphics which could affect content, and all legal disclaimers and ethical guidelines that apply to the journal pertain. ACS cannot be held responsible for errors or consequences arising from the use of information contained in these "Just Accepted" manuscripts. 


\title{
Electropolymerized Star-Shaped Benzotrithiophenes
}

\section{Yield $\pi$-Conjugated Hierarchical Networks with}

\section{High Areal Capacitance}

\author{
Andreas Ringk, ${ }^{\perp}$ Adrien Lignie, ${ }^{\perp}$ Yuanfang Hou, Husam N. Alshareef, and Pierre M. Beaujuge ${ }^{*}$ \\ Physical Sciences \& Engineering Division, King Abdullah University of Science \& Technology \\ (KAUST), Thuwal 23955-6900, Saudi Arabia.
}

KEYWORDS: Supercapacitor, conjugated polymers, benzotrithiophene, star-shaped motifs, high areal capacitance.

\begin{abstract}
High-surface-area $\pi$-conjugated polymeric networks have the potential to lend outstanding capacitance to supercapacitors because of the pronounced faradaic processes that take place across the dense intimate interface between active material and electrolytes. In this report, we describe how benzo[1,2-b:3,4- $\left.b^{\prime}: 5,6-b^{\prime}{ }^{\prime}\right]$ trithiophene $\quad$ (BTT) and tris(ethylenedioxythiophene)benzo[1,2-b:3,4- $b^{\prime}: 5,6-b^{\prime \prime}$ '] trithiophene (TEBTT) can serve as 2D (trivalent) building blocks in the development of electropolymerized hierarchical $\pi$-conjugated frameworks with particularly high areal capacitance. In comparing electropolymerized networks
\end{abstract}


of BTT, TEBTT, and their copolymers with EDOT, we show that TEBTT/EDOT-based copolymers, i.e. $\mathrm{P}($ TEBTT/EDOT), can achieve higher areal capacitance (e.g., as high as 443.8 $\mathrm{mF} \mathrm{cm}$ at $1 \mathrm{~mA} \mathrm{~cm}^{-2}$ ) than those achieved by their respective homopolymers (PTEBTT and PEDOT) in the same experimental conditions of electrodeposition (PTEBTT: $271.1 \mathrm{mF} \mathrm{cm}^{-2}$ (at $1 \mathrm{~mA} \mathrm{~cm}^{-2}$ ) and PEDOT: $12.1 \mathrm{mF} \mathrm{cm}^{-2}\left(\right.$ at $\left.1 \mathrm{~mA} \mathrm{~cm}^{-2}\right)$ ). For example, P(TEBTT/EDOT)-based frameworks synthesized in a 1:1 monomer-to-comonomer ratio show a ca. 35x capacitance improvement over PEDOT. The high areal capacitance measured for P(TEBTT/EDOT)-based frameworks can be explained by the open, highly porous hierarchical morphologies formed during the electropolymerization step. With $>70 \%$ capacitance retention over 1,000 cycles (up to 89\% achieved), both PTEBTT- and P(TEBTT/EDOT)-based frameworks are resilient to repeated electrochemical cycling and can be considered promising systems for high life cycle capacitive electrode applications.

\section{INTRODUCTION}

Of all electrochemical devices capable of storing charge and delivering power, highpower-density and high-energy-density supercapacitors with extensive life cycles are especially attractive for applications such as portable electronics and electric vehicle powertrains. ${ }^{1,2}$ Comparatively, high-power densities (i.e., fast charge-discharge rates) can be more readily achieved than high-energy densities in electrochemical capacitors because of the nature of the charge storage process. ${ }^{3}$ For supercapacitors, a wide range of material systems, including metal oxides $^{3}$ and conjugated polymers, ${ }^{4,5}$ are being explored for their inclusion in the development of higher-performing electrode materials that combine high energy and power densities. Some pseudocapacitive materials can yield energy densities as high as $300 \mathrm{Wh} \mathrm{kg}^{-1}$ (at power densities 
of $\left.0.47 \mathrm{~kW} \mathrm{~kg}^{-1}\right),{ }^{6}$ while pure-electric double-layer capacitors yield significantly lower figures of ca. $10 \mathrm{Wh} \mathrm{kg}^{-1}$ (at $\left.1 \mathrm{~A} \mathrm{~g} \mathrm{~g}^{-1}\right){ }^{7}$ In addition to the intrinsic pseudocapacitive properties of oxides and polymers, their nano- and meso-scale morphologies and the interplay between material surface and electrolytes are critical to optimizing the capacitance of electrode material and thus, overall supercapacitor performance. Considering both morphology and material/electrolyte interactions, conjugated polymers that can be electropolymerized into highly porous networks are promising pseudocapacitive materials for use in the construction of supercapacitors for specific applications. ${ }^{8-10}$ Electropolymerization approaches using monomer solutions can be performed reproducibly, while incorporating ions and counterions in the process of forming open, porous nanostructured films. ${ }^{11,12}$ Thus, several studies have emphasized the range of achievable morphologies using conjugated polymers such as polyaniline (PANI), ${ }^{13,14}$ polypyrrole, ${ }^{14,} 15$ polythiophene, ${ }^{16}$ and poly(3,4-ethylenedioxythiophene) (PEDOT) ${ }^{17}$, 18 , derived from the electropolymerization of commercially available monomers. For example, varying the experimental conditions for the synthesis of PANI induces considerable morphological changes that impact material capacitance (i.e., nanospheres to nanorods to nanofibers). ${ }^{19}$

Another approach to tuning polymer film morphology relies on the development of functional monomers that can adopt other specific electrodeposition patterns upon electrochemical polymerization including multivalent monomers or comonomers that form $2 \mathrm{D}$ or $3 \mathrm{D}$ covalent networks. ${ }^{20,21}$ For example, phenylenevinylene- ${ }^{20}$ phenylethynylene- ${ }^{21}$ and triazine-based ${ }^{21}$ motifs have been shown to yield highly porous morphologies with specific surface values $>1,000$ $\mathrm{m}^{2} \mathrm{~g}^{-1}$ in specific experimental electrodeposition conditions, while trivalent motifs such as $1,3,5-$ tris(oligothienyl)benzene $\mathrm{e}^{22,23}$ and triarylamine ${ }^{24-27}$ are amenable to synthesizing efficient capacitive conjugated networks. In parallel, the copolymerization of monomers with comparable 
oxidation potentials, such as $2,2^{\prime}$-bithiophene and triphenylamine $(10 \mathrm{~mol} \%)$ motifs, ${ }^{26}$ is another promising strategy for the preparation of tunable capacitive polymeric frameworks.

In this report, we compare the electropolymerization patterns of two $2 \mathrm{D}$ (trivalent) building blocks - benzo[1,2- $b: 3,4-b^{\prime}: 5,6-b$ '’ ]trithiophene (BTT) and tris(ethylenedioxythiophene)benzo[1,2-b:3,4- $b^{\prime}: 5,6-b^{\prime \prime}$ '] trithiophene (TEBTT) (Scheme 1) - and their copolymerization with 3,4-ethylenedioxythiophene (EDOT). We also describe the experimental conditions required to form hierarchical $\pi$-conjugated frameworks with particularly high areal capacitance. Based on the basic characterization of BTT-based well-defined oligomers $^{28,29}$ and TEBTT homopolymers from previous reports,${ }^{30}$ we clarify the fundamental differences between electropolymerized homopolymer and copolymer networks made from these two building motifs, and emphasize their use for the synthesis of high-capacitance, nanostructured 3D polymeric networks that are resilient to repeated electrochemical cycling. In particular, comparing BTT- and TEBTT-based networks, we find that TEBTT-based homopolymers and copolymers with EDOT are substantially more capacitive (reaching up to $271.1 \mathrm{mF} \mathrm{cm}^{-2}$ and $443.8 \mathrm{mF} \mathrm{cm} \mathrm{cm}^{-2}\left(1 \mathrm{~mA} \mathrm{~cm}^{-2}\right)$, respectively) and stable upon cycling (up to $73 \%$ and $89 \%$ capacitance retention after 1,000 cycles, respectively) than their BTT counterparts. 
(a)

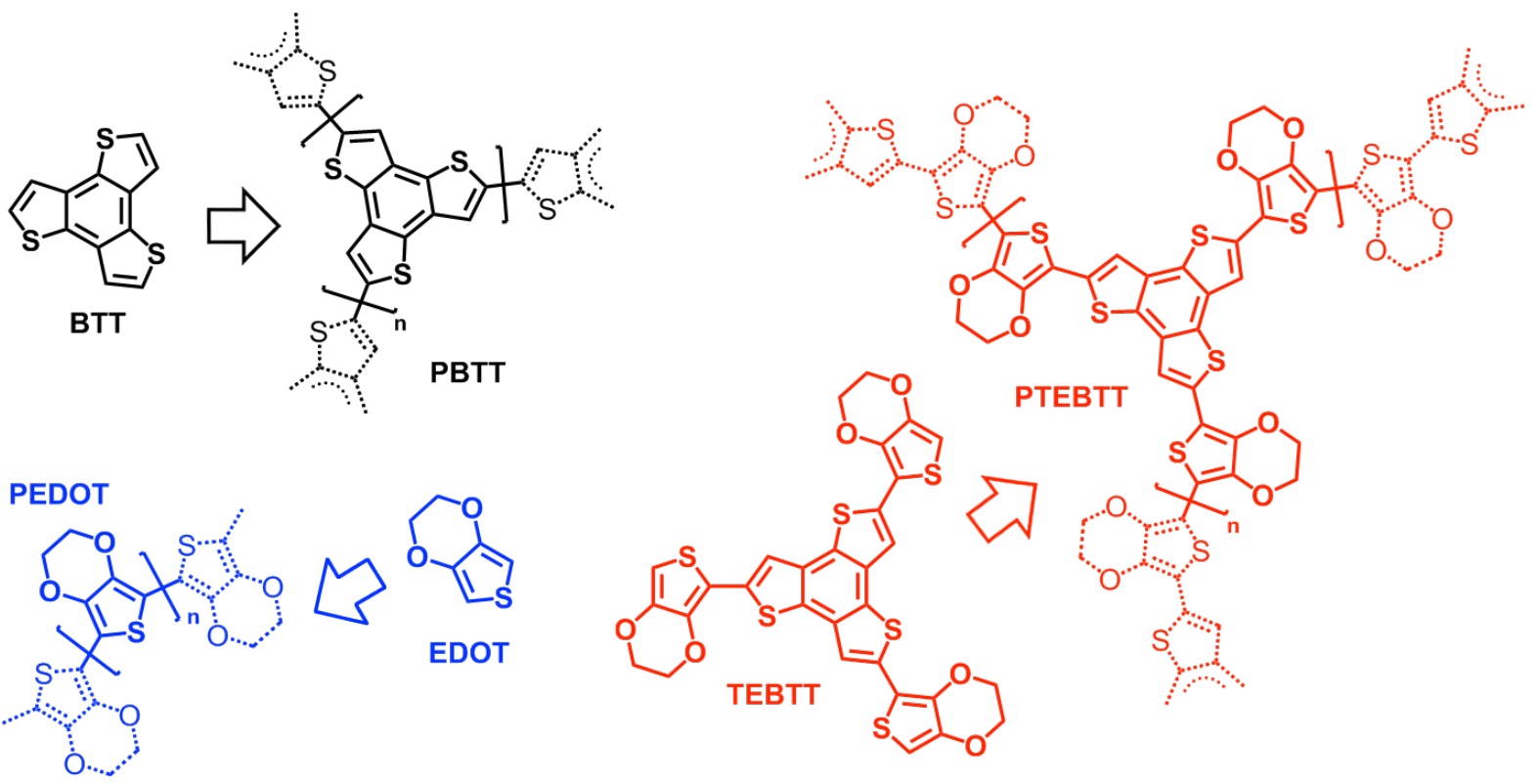

(b)
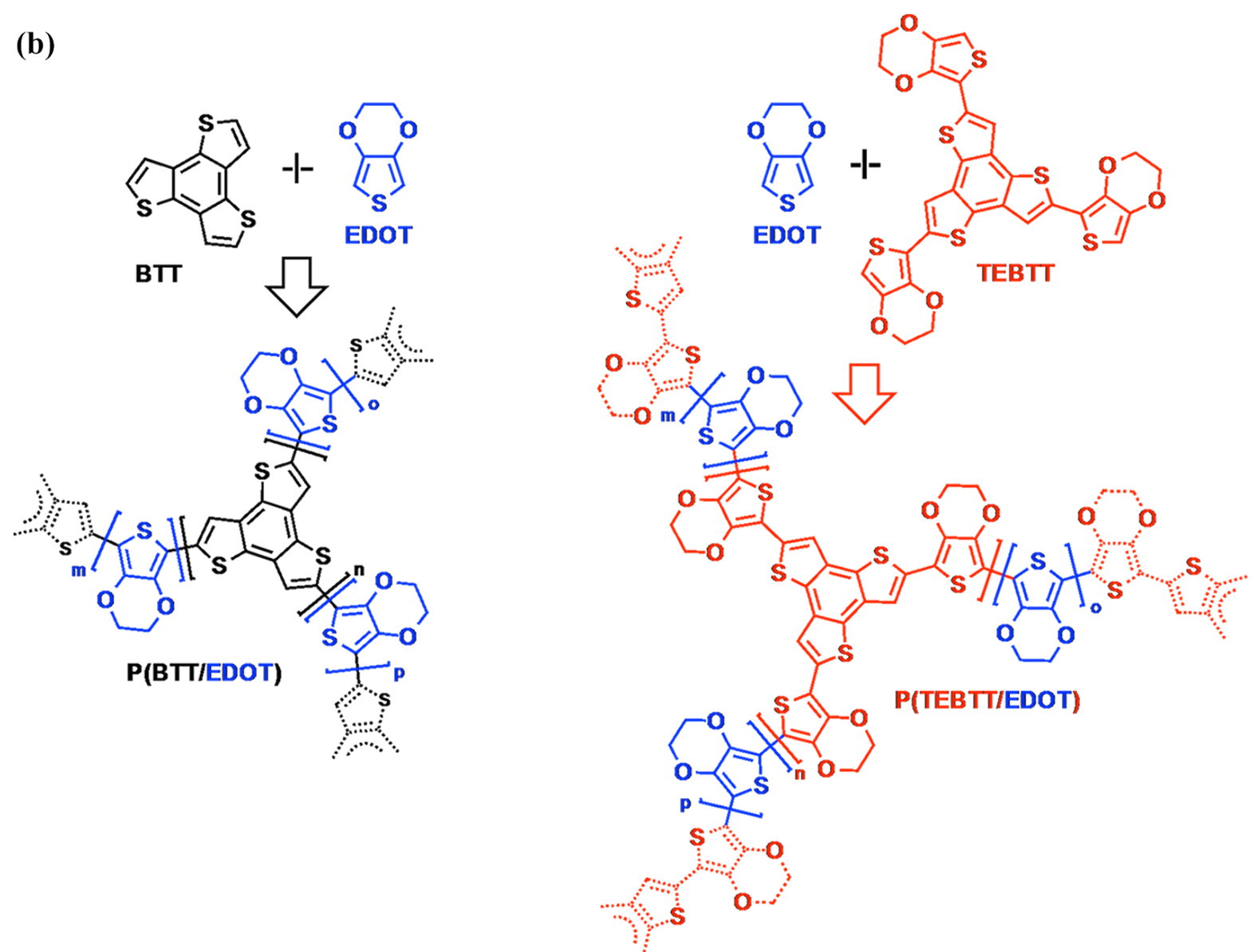

Scheme 1 (a) Schematic representation of 3,4-ethylenedioxythiophene (EDOT), benzo[1,2$b: 3,4-b^{\prime}: 5,6-b^{\prime \prime}$ '] trithiophene $\quad$ (BTT), tris(ethylenedioxythiophene)benzo[1,2- $b: 3,4-b ': 5,6-$ 
b' ']trithiophene (TEBTT), and their respective polymers (PEDOT, PBTT, and PTEBTT). (b)

Schematic representation of the random copolymerization of BTT and TEBTT with EDOT.

\section{METHODS}

Synthetic Procedures. Benzo[1,2-b:3,4- $\left.b^{\prime}: 5,6-b^{\prime}{ }^{\prime}\right]$ trithiophene ${ }^{27} \quad$ (BTT) and tris(ethylenedioxythiophene)benzo[1,2-b:3,4- $b^{\prime}: 5,6-b^{\prime \prime}$ '] trithiophene ${ }^{30} \quad$ (TEBTT) were synthesized according to previously reported methods. The Supporting Information (SI) provides the details of the synthetic protocols. All monomers were characterized by ${ }^{1} \mathrm{H} \mathrm{NMR}(400 \mathrm{MHz})$ and ${ }^{13} \mathrm{C}$ NMR (100 MHz) on a Bruker Advance III Ultrashielded 400 Plus instrument at room temperature. The ${ }^{1} \mathrm{H},{ }^{13} \mathrm{C}$ NMR spectra were referenced according to the tetramethylsilane (TMS) internal standards. High-resolution mass spectrometry (HRMS) data was recorded using an LTQ Orbitrap Velos MS (Thermo Fisher Scientific) in the positive atmospheric pressure photoionization (+APPI) mode. Elemental analyses were performed on a Flash 2000 - Thermo Scientific CHNO Analyzer.

Electrochemical Measurements. The electrochemical characterizations were performed in a standard three-electrode cell placed in a nitrogen-filled glovebox to which a Versastat 4 potentiostat/galvanostat (Princeton Instrument) was connected. In all three-electrode cell experiments, a nonaqueous $\mathrm{Ag} / \mathrm{Ag}^{+}$electrode [consisting of a $\mathrm{Ag}$ wire immersed in a $10 \mathrm{mM}$ $\mathrm{AgNO}_{3}$ and $100 \mathrm{mM}$ tetrabutylammonium perchlorate (TBAP) solution] was used as the reference electrode, and a platinum wire was used as the counter electrode. The working electrode consisted of a gold button electrode (7 mm-diameter electrode fitted with $3 \mathrm{~mm}$ diameter gold disc), a carbon cloth $\left(\mathrm{ca} .1 \mathrm{~cm}^{2}\right)$, a platinum button electrode $(7 \mathrm{~mm}$-diameter electrode fitted with $3 \mathrm{~mm}$-diameter platinum disc), or a glassy carbon electrode (7 mm-diameter 
electrode fitted with $3 \mathrm{~mm}$-diameter glassy carbon disc). Figure S11 shows the cyclic voltammogram of Ferrocene, used as standard; measurements performed in $100 \mathrm{mM}$ tetrabutylammonium hexafluorophosphate $\left(\mathrm{TBAPF}_{6}\right)$ in acetonitrile $(\mathrm{ACN})$. All electrolyte solutions were prepared using anhydrous ACN or dichloromethane (DCM) solvents and with 100 $\mathrm{mM} \mathrm{TBAPF}_{6}$ as the supporting electrolyte.

Linear scan voltammograms of BTT, TEBTT, and EDOT were collected on gold button electrodes at a scan rate of $20 \mathrm{mV} \mathrm{s}^{-1}$ from solutions of 5,1 , and $5 \mathrm{mM}$ in DCM respectively (a lower molarity of TEBTT was used for solubility reasons). The (BTT/EDOT)-based copolymers, i.e. $\mathrm{P}(\mathrm{BTT} / \mathrm{EDOT})$, were electrodeposited on highly porous conducting carbon cloth from several monomer solutions of different BTT/EDOT monomer compositions (1:0, 3:1, 1:1, 1:3, 1:6, and 0:1). The electrodeposition experiments (20 cycles) were performed in ACN in a potential window of $-0.7-+1.6 \mathrm{~V}$ and with a scan rate of $50 \mathrm{mV} \mathrm{s}{ }^{-1}$. P(TEBTT/EDOT) was prepared on glassy carbon electrodes from several monomer solutions (see Table 1) of different TEBTT/EDOT monomer compositions (1:0, 3:1, 1:1, 1:3, 1:9, 5:95, and 0:1) in DCM, and 20 deposition cycles at a scan rate of $50 \mathrm{mV} \mathrm{s}^{-1}$ in a voltage window of $-1.0-+1.2 \mathrm{~V}$ (vs. $\mathrm{Ag} / \mathrm{Ag}^{+}$) unless otherwise specified. The analysis of the capacitive performances of the electrodeposited materials was performed in ACN.

The areal capacitance $(\mathrm{Ca})$ of electrodeposited polymeric materials was calculated from the charge-discharge curves using the following general equation: ${ }^{31}$

$$
C a=I^{*} \Delta t / \Delta \mathrm{V}
$$


where $C a$ is expressed in $\mathrm{mF} \mathrm{cm}{ }^{-2}$ and the constant current (I) is applied in $\mathrm{mA} \mathrm{cm}^{-2} ; \Delta \mathrm{t}$ is the discharging time (in seconds) and $\Delta \mathrm{V}$ is the potential change (in $\mathrm{V}$ ). ${ }^{31} \mathrm{In}$ this report, we discuss and emphasize $C a$ values (as opposed to the gravimetric capacitance $C s$ ) by using a measurement of the functionalized surface area that is more accurate than measuring the exact mass of the electrodeposited polymeric material.

Imaging Characterization. Electrodeposited polymer film morphologies were characterized with a Quanta 600 scanning electron microscope (SEM) (FEI). Prior to imaging the samples, the supporting electrolyte was washed from the electropolymerized thin film by successive rinsing steps in neat ACN, and a $5 \mathrm{~nm}$ layer of gold was sputtered onto the polymer films (to minimize charging effects). The SEM was operated at a working distance of $5 \mathrm{~mm}$ and an accelerating potential of $10 \mathrm{kV}$.

\section{RESULTS AND DISCUSSION}

\section{Electrochemical Characterizations of BTT and TEBTT}

Figure 1a shows the linear scans in potential and actual onsets of oxidation for BTT, TEBTT, and EDOT (control scan); the various oxidation features observed for BTT and TEBTT on scanning linearly in the $-2.0-+2.5 \mathrm{~V}$ potential window (vs. $\mathrm{Ag} / \mathrm{Ag}^{+}$) are detailed directly on the plots in Figures $1 \mathrm{~b}$ and $1 \mathrm{c}$, respectively (oxidation potentials taken at the maximum peak height). In all three experiments, a dark electrodeposited film forms on the gold button electrode, indicating that electropolymerization is occurring during linear scans. BTT exhibits three wellpronounced oxidation peaks at $+1.28 \mathrm{~V}\left(\mathrm{E}_{\mathrm{ox} 1}\right),+1.59 \mathrm{~V}\left(\mathrm{E}_{\mathrm{ox} 2}\right)$, and $+2.04 \mathrm{~V}\left(\mathrm{E}_{\mathrm{ox} 3}\right)$. Interestingly, prior studies of BTT-based systems via cyclic voltammetry (CV) have only described one oxidation peak, albeit at different potentials of $+1.39 \mathrm{~V}$ (vs. $\mathrm{Ag} / \mathrm{AgCl})^{30}$ and $+1.55 \mathrm{~V}$ (vs. 
$\mathrm{Ag} / \mathrm{AgCl}):{ }^{29}$ we note that the oxidation feature observed in the prior study ${ }^{30}$ was somewhat broad and likely encompassed oxidation peaks $\mathrm{E}_{\mathrm{ox} 1}$ and $\mathrm{E}_{\mathrm{ox} 2}$ similar to those shown in Figure 1b (no cyclic voltammogram was provided in the later study). The first oxidation peak seen for BTT $\left(\mathrm{E}_{\mathrm{ox} 1}=+1.28 \mathrm{~V}\right)$ is sharp and has an onset at $+1.11 \mathrm{~V}$, on the same order of that observed for EDOT $(+1.02 \mathrm{~V}$; Fig. 1a) and similar to that reported for terthiophene $($ ca. $+1.0 \mathrm{~V}$; vs. $\left.\mathrm{Ag} / \mathrm{Ag}^{+}\right) .{ }^{32,33}$ This oxidation onset of BTT is, however, significantly lower than that of singlering thiophene motifs $\left(\mathrm{ca} .+1.75 \mathrm{~V}\right.$; vs. $\left.\mathrm{Ag} / \mathrm{Ag}^{+}\right){ }^{33}$ illustrating how redox potential depends on conjugation length and HOMO-LUMO gap reduction in more extended BTT $\pi$-systems. ${ }^{33}$ The second and third oxidation features in the linear scan of BTT occur at $\mathrm{E}_{\mathrm{ox} 2}=+1.59 \mathrm{~V}$ and $\mathrm{E}_{\mathrm{ox} 3}=$ $+2.04 \mathrm{~V}$. The origin of these sequential oxidations is unclear, as those may arise from a sequential oxidation of the thiophene rings of BTT to radical cations or stem from the formation of coupled products resulting from the initial oxidation step (thiophene-based cation radicals to form oligomeric species). ${ }^{34}$
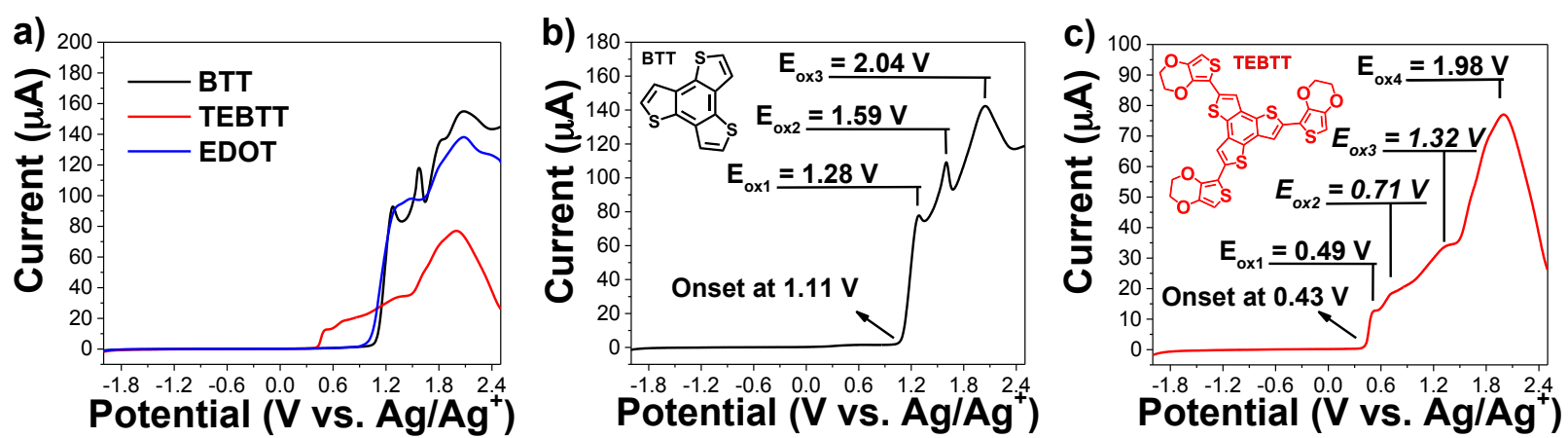

Figure 1 (a) Linear scan voltammograms collected on gold button electrodes at a scan rate of 20 $\mathrm{mV} \mathrm{s}^{-1}$ from a solution of BTT $(5 \mathrm{mM})$, TEBTT $(1 \mathrm{mM})$, and EDOT $(5 \mathrm{mM})$ in DCM. (b, c) Individual linear scan voltammograms detailing (b) BTT's and (c) TEBTT's oxidation features; the values italicized point to oxidation features that are not well resolved but occur reproducibly between experiments. 
The early oxidation onset of TEBTT (Fig. 1c) at $+0.43 \mathrm{~V}$ is comparably much lower than that of BTT, which is expected because of the EDOT unit substitution on the BTT core, further extending the $\pi$-conjugated motif. Here, the oxidation potential of TEBTT measured by linear scan is lower that that reported in earlier work by $\mathrm{CV}(+0.78 \mathrm{~V} \text {; vs. } \mathrm{Ag} / \mathrm{AgCl})^{30}$. Figure $1 \mathrm{c}$ provides further insight on the consecutive oxidation features in TEBTT, although it should be noted that the second and third oxidation features $\left(\mathrm{E}_{\mathrm{ox} 2}=+0.71 \mathrm{~V}\right.$ and $\left.\mathrm{E}_{\mathrm{ox} 3}=+1.32 \mathrm{~V}\right)$ are somewhat convoluted in the broad redox response of TEBTT in this voltage window. While the first oxidation peaks $\left(\mathrm{E}_{\mathrm{ox} 1}=+0.49 \mathrm{~V}\right)$ can be assigned to the oxidation of an EDOT motif in TEBTT, several processes can be at the origin of the three following oxidation features $\left(\mathrm{E}_{\mathrm{ox} 2}=\right.$ $+0.71 \mathrm{~V}, \mathrm{E}_{\mathrm{ox} 3}=+1.32 \mathrm{~V}$, and $\mathrm{E}_{\mathrm{ox} 4}=+1.98 \mathrm{~V}$ ) and those discussions are beyond the scope of this study.

\section{Copolymerization of BTT and EDOT}

Considering the close oxidation potentials of BTT $\left(\mathrm{E}_{\mathrm{ox} 1}=+1.28 \mathrm{~V}\right.$; Fig. 1b) and EDOT $(+1.02$ V; Fig. 1a), the concurrent electropolymerization of the two motifs can be expected to yield copolymers with random compositions. Because PEDOT is one of the most conductive and capacitive polymers reported to date,,$^{1,17,35}$ copolymers of BTT and EDOT may combine highcapacitance, nanostructured networks that are inherently distinct from those of their respective homopolymers (PBTT and PEDOT). Thus, we examined the electrodeposition of $\mathrm{P}(\mathbf{B T T} / \mathrm{EDOT})$ prepared from several monomer solutions of different BTT/EDOT monomer compositions; experiments were performed in ACN on highly porous conducting carbon cloth with a potential window of $-0.7-+1.5 \mathrm{~V}$ and a scan rate of $50 \mathrm{mV} \mathrm{s}^{-1}$ for 20 cycles. The SEM images shown in Figure 2 illustrate the morphologies of the electrodeposited PBTT (Fig. 2a; 1:0 ratio in BTT/EDOT), BTT/EDOT-based copolymers (Fig. 2b, 2c, 2d, and 2e; 3:1, 1:1, 1:3, and 
1:6 ratios, respectively), and PEDOT (Fig. 2f; 0:1 ratio). Comparing the film depositions achieved in Figures 2a (PBTT) and 3f (PEDOT), the contrasts in electrodeposition yields and morphologies formed on the carbon cloth electrodes are rather obvious, and it is interesting to note that BTT may not electropolymerize as efficiently as EDOT in spite of their comparable onsets of oxidation. This might be explained by the lower conductivity of PBTT compared to PEDOT (although challenging to measure in non-continuous electropolymerized films), which may affect the propensity of the BTT monomer to electropolymerize further once a critical amount of PBTT is deposited on the carbon cloth. In contrast to the dense nodular morphology and large aggregates (700-2,500 nm) obtained on electropolymerizing EDOT (Fig. 2f), sparser aggregates with high aspect ratios are observable for PBTT (width dispersion: 80-160 nm; length: 400-700 nm). Looking at the intermediate morphologies that develop on copolymerizing BTT and EDOT (depicted in Figures 2b, 2c, 2d, and 2e), it is worth noting however that electrodeposited films of $\mathrm{P}(\mathbf{B T T} / \mathrm{EDOT})$ are more densely nanostructured than those of their PBTT counterpart, showing significant differences in aggregate size distributions. In general, blending BTT and EDOT leads to the electrodeposition of aggregate patterns that are somewhat smaller in size (i.e., more nanostructured) compared to PEDOT films and dependent on the initial BTT/EDOT monomer ratios (Fig. 2b, 3:1 ratio in BTT/EDOT, aggregates: 30-300 nm; clusters: 500-1,000 nm; Fig. 2c, 1:1 ratio in BTT/EDOT, clusters: 400-2,000 nm; Fig. 2d, 1:3 ratio in BTT/EDOT, aggregates: ca. $40 \mathrm{~nm}$; clusters: 1,000-2,000 nm; Fig. 2e, 1:6 ratio in BTT/EDOT, clusters: 200-1,400 nm). 

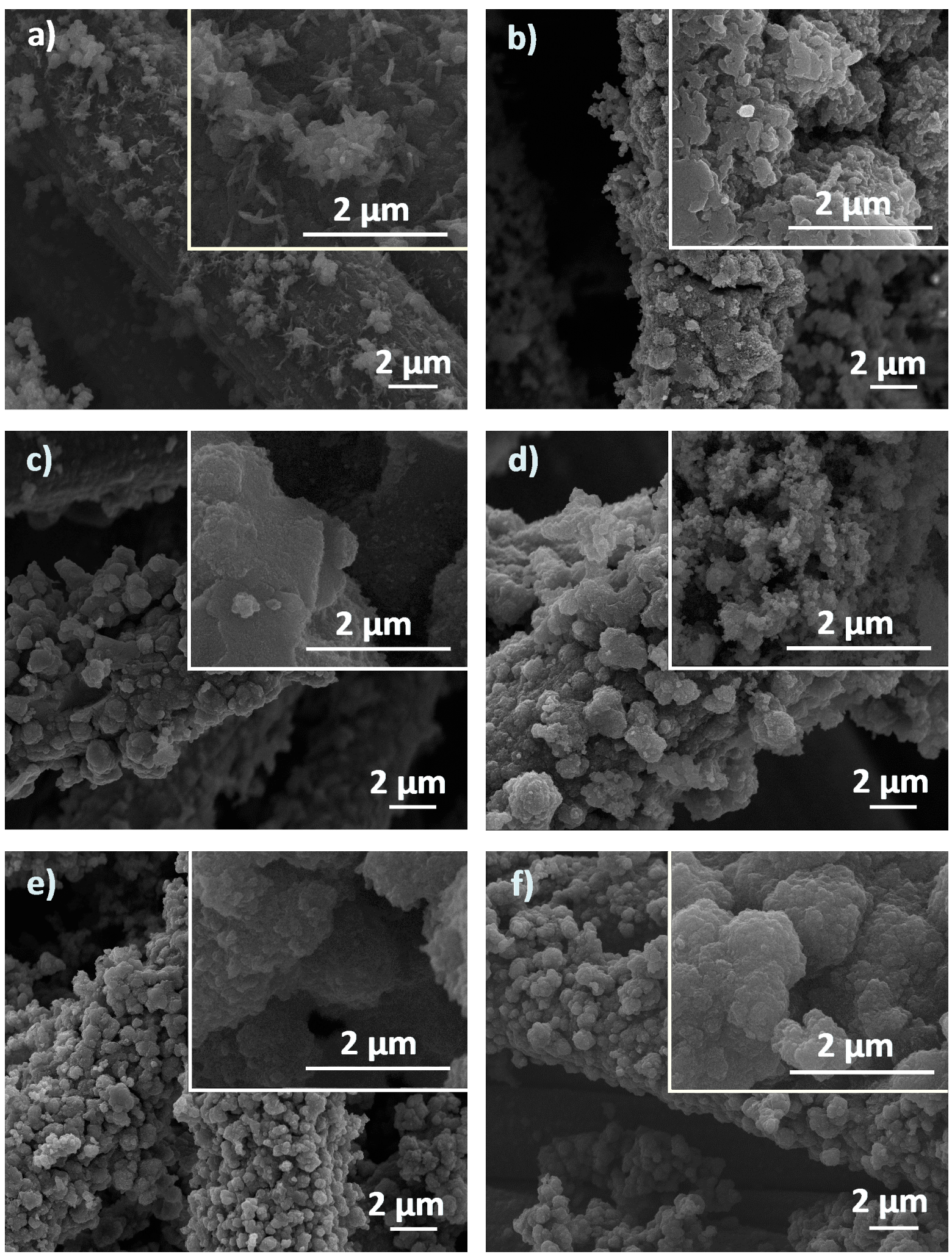

Figure 2 SEM images of the morphologies of electrodeposited polymer films prepared from several monomer solutions of different BTT/EDOT monomer compositions: (a) 1:0, (b) 3:1, (c) 
$1: 1$, (d) $1: 3$, (e) 1:6, and (f) $0: 1$. Electrodeposition conditions: $50 \mathrm{mM}$ monomer solutions in $\mathrm{ACN} ; 20$ deposition cycles in a voltage window of $-0.7-+1.5 \mathrm{~V}$ (vs. $\mathrm{Ag} / \mathrm{Ag}^{+}$), on carbon cloth electrodes; deposition scan rate of $50 \mathrm{mV} \mathrm{s}^{-1}$.

The electroactivity and capacitive properties of PBTT, PEDOT, and P(BTT/EDOT) were measured by $\mathrm{CV}$; the corresponding voltammograms are shown in Figures $3 \mathrm{a}$ and $3 \mathrm{~b}$. For ease of comparison, each voltammogram is normalized to the extent of functionalized surface area, and in Figure $3 \mathrm{c}$ the areal capacitance $(\mathrm{Ca})$ of the electrodeposited polymers is extracted from galvanostatic charge-discharge measurements (the values are shown directly on the plot). By comparing all electrodeposited systems in Figure 3, we note that PBTT homopolymers exhibit only a modest capacitance value of $73 \mathrm{mF} \mathrm{cm}^{-2}$ (at $5 \mathrm{~mA} \mathrm{~cm}$ ), which is consistent with the lack of reversibility of the broad redox process in the 0.0 to $+0.8 \mathrm{~V}$ voltage window and with the smaller amount of material deposited on the carbon cloth electrode (Fig. 2a). It is interesting to note, however, that considering recently published studies on electropolymerized material systems for supercapacitor applications, ${ }^{35-38} \mathrm{Ca}$ values $>50 \mathrm{mF} \mathrm{cm}{ }^{-2}$ inferred for PBTT remain significant. For comparison, polypyrrole/graphene oxide nanocomposites have been shown to yield $22.8 \mathrm{mF} \mathrm{cm}^{-2}$ (at $\left.0.1 \mathrm{~mA} \mathrm{~cm}^{-2}\right),{ }^{38}$ while poly(3,4-propylenedioxypyrrole/SWCNT composites attain $16.4 \mathrm{mF} \mathrm{cm}^{-2}$ (at $\left.0.9 \mathrm{~mA} \mathrm{~cm}^{-2}\right){ }^{36}$ capacitance values that are expected to drop significantly at higher current densities, such as those at which we estimate the capacitance of PBTT (i.e., $5 \mathrm{~mA} \mathrm{~cm}^{-2}$ ).

Following the same experimental conditions as those used for the electrodeposition of PBTT, PEDOT-functionalized carbon cloth electrodes yield $C a$ values of $733 \mathrm{mF} \mathrm{cm}^{-2}$ (at $5 \mathrm{~mA} \mathrm{~cm}^{-2}$ ), confirming that PBTT homopolymers perform more modestly than PEDOT. Here again, these differences may arise from the lower electronic conductivity of PBTT compared to PEDOT, 
noting that the thiophene rings in BTT motifs are not in direct conjugation because the central phenyl interferes with the conjugation path between thiophenes. The significant voltage drops (IR-drop) visible in Figure $3 \mathrm{c}$ ( $2 \mathrm{x}$ that seen for PEDOT electropolymerized in the same conditions) reflect energy losses due to internal resistance in films of electrodeposited PBTT, further supporting the argument consistent with the idea that PBTT films may be less conductive than those of PEDOT. It should also be noted that the occurrence of $\alpha-\beta$ and $\beta-\beta$ couplings in unsubstituted thiophene-based motifs subjected to oxidative polymerization conditions are known to affect conjugation, and subsequently lower the conductivity, electrochemical cycling stability, and capacitive performance of thiophene-based polymers. ${ }^{33,39,40}$ In parallel, and as shown in Figure 3, the capacitive cycles of the several P(BTT/EDOT) copolymers (see Scheme 1b) electrodeposited and characterized by $\mathrm{CV}$ reflect redox behaviors that are somewhat intermediate between those of PBTT and PEDOT. A similar pattern is observed for areal capacitance values, suggesting that long segments of the two homopolymers formed on the carbon cloth electrode. 

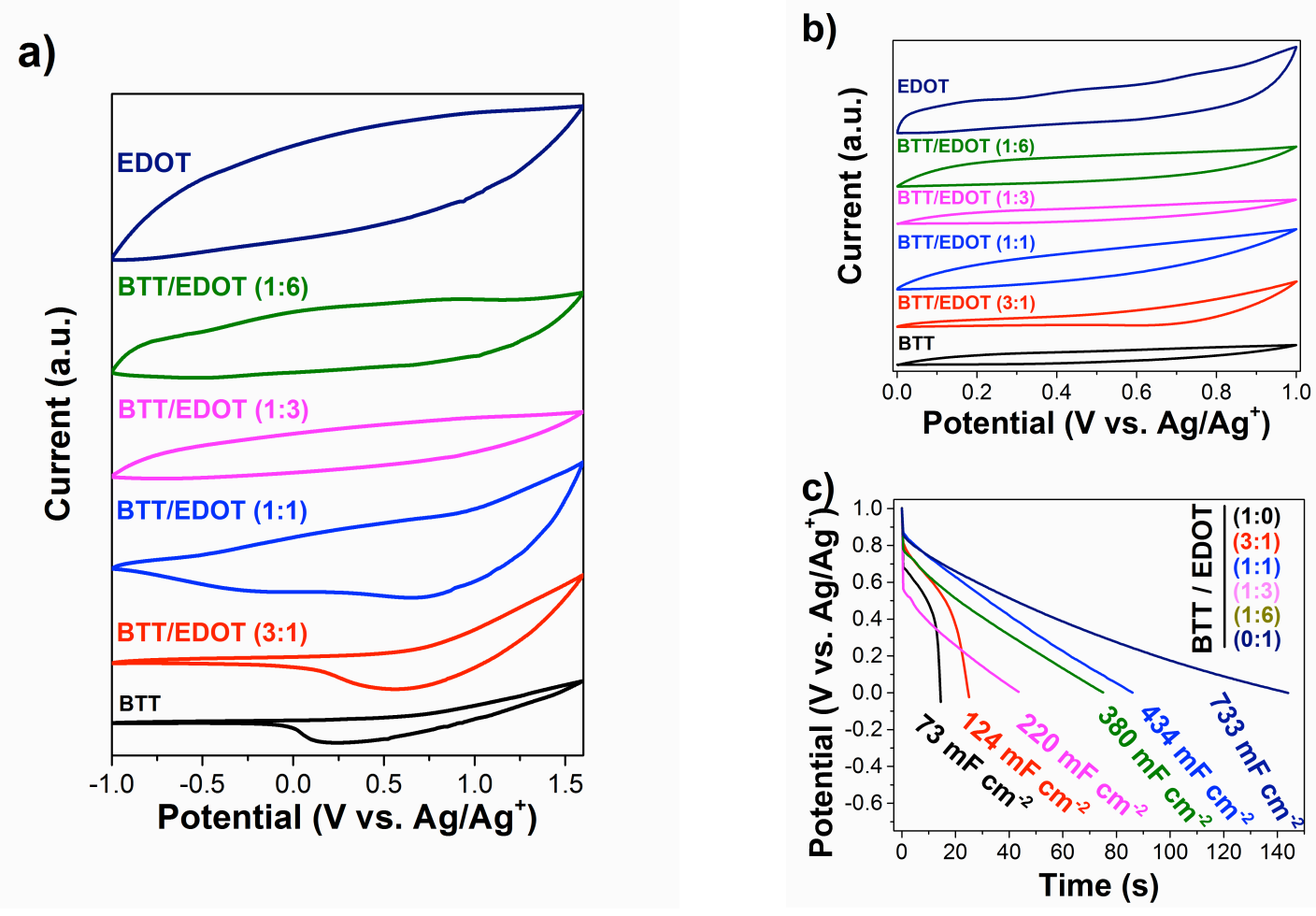

Figure 3 (a, b) Cyclic voltammograms of electrodeposited PBTT, PEDOT, and several BTT/EDOT-based copolymers prepared from several solutions of different BTT/EDOT monomer compositions: 1:0 (black), 3:1 (red), 1:1 (blue), 1:3 (magenta), 1:6 (green), and 0:1 (dark blue) at a scan rate of $20 \mathrm{mV} \mathrm{s}^{-1}$ (Note: insets a) and b) show different potential windows). Electrodeposition conditions: $50 \mathrm{mM}$ monomer solutions in $\mathrm{ACN}$; 20 deposition cycles in a voltage window of $-0.7-+1.6 \mathrm{~V}\left(\mathrm{vs} . \mathrm{Ag} / \mathrm{Ag}^{+}\right.$), on carbon cloth electrodes; deposition scan rate of $50 \mathrm{mV} \mathrm{s}^{-1}$. Each voltammogram is normalized to the extent of functionalized surface area. (c) Galvanostatic charge-discharge curves collected for the polymers at a current density of $5 \mathrm{~mA}$ $\mathrm{cm}^{-2}$; the areal capacitance values inferred are indicated on the plot.

\section{Copolymerization of TEBTT and EDOT}

As an alternative to BTT, and to mitigate the probability of $\alpha-\beta$ and $\beta$ - $\beta$ couplings between the thiophene moieties, we turn to the TEBTT motifs, where EDOT units were appended to the 
BTT core, extending the conjugation of the $\pi$-system and further reducing its HOMO/LUMO gap..$^{33}$ As a result, and as previously discussed from Figure 1c, TEBTT exhibits a lower oxidation potential $\left(\mathrm{E}_{\mathrm{ox} 1}=+0.49 \mathrm{~V}\right)$. Because TEBTT is a more extended $\pi$-conjugated system, $\pi$-stacking and aggregation make it only moderately soluble in ACN, but its solubility was found sufficient in DCM (solubility up to $1.25 \mathrm{mM}$ ), and the later was used for the electrochemical polymerization of all TEBTT-based polymers. Next, the electrodeposited films were carefully rinsed with DCM and characterized in ACN for consistency with the characterization protocol used for all BTT-based polymers.

First, we studied the optimal conditions for the electrochemical deposition of PTEBTT as a function of voltage window, cycle number, and working electrode with the goal of achieving the best possible $\mathrm{Ca}$ values. The corresponding experimental conditions and obtainable $\mathrm{Ca}$ values are summarized in Table 1. Figure 4a shows the CV curves of PTEBTT films electrodeposited on various working electrodes and voltage windows. In contrast to the lack of reversibility of the broad redox process previously discussed for PBTT, the redox processes for PTEBTT were found to be inherently more reversible (see Figure S12). As emphasized in Table 1 and Figure 4a, a voltage window of $-0.2-+0.8 \mathrm{~V}$ was found optimal for PTEBTT with respect to the $C a$ performance values. The choice of the working electrode (WE) was also found to be an important parameter, with glassy carbon (GC) button electrodes producing polymer films that are electroactive and reversibly cycled over a broader voltage range, suggesting a more adhered, more densely electropolymerized polymeric network (found to yield higher $\mathrm{Ca}$ values). In contrast, attempts to electrodeposit TEBTT on carbon cloth and indium tin oxide (ITO) electrodes did not yield comparably promising results and thus, were not pursued further. Furthermore, because films electrodeposited via alternative deposition techniques such as 
potentiostatic and pulsed potentiostatic techniques showed only modest capacitive characteristics, we concentrated on CV protocols (Table 1). PTEBTT films electrodeposited on the GC electrode exhibit an oxidation onset at $+0.20 \mathrm{~V}$ (Fig. 4a) and a broad quasi-reversible redox couple $\left(\mathrm{E}_{\mathrm{ox} 1}=+0.62 \mathrm{~V}-\mathrm{E}_{\mathrm{red} 1}=+0.27 \mathrm{~V}\right)$ followed by an irreversible oxidation (and related reduction $\mathrm{E}_{\mathrm{red} 2}=+0.69 \mathrm{~V}$ on the reverse cycle). The SEM image in Figure 5a shows a distinctly structured morphology on micron-sized fibers densely distributed across the GC surface (width dispersion: 150-200 nm; length: 1,200-1,600 nm) accompanied by some nodular aggregates (800-1,600 nm). From the optimized conditions (WE: glassy carbon button electrode, voltage window: $-1.0-+1.2 \mathrm{~V}$, scan rate: $50 \mathrm{mV} \mathrm{s}^{-1}$ ), we studied the dependence of the capacitive response of PTEBTT as a function of the number of electrodeposition cycles and the scan rate; the corresponding CV curves are shown in Figures 4b and 4c. Overall, with PTEBTT, $C a$ values are found to increase with the number of electrodeposition cycles as more electroactive material is deposited on the GC electrode, reaching areal capacitance values as high as $271.1 \mathrm{mF} \mathrm{cm}^{-2}(1$ $\mathrm{mA} \mathrm{cm} \mathrm{cm}^{-2}$ ) after 120 cycles, which represents a 10-fold improvement compared to PBTT. In addition to the high $C a$ values achieved, Figures $4 \mathrm{~b}$ and $4 \mathrm{c}$ emphasize the reversibility of the first redox couple in PTEBTT, which is maintained for films obtained over large numbers of deposition cycles (up to 120 shown in Fig. 4b) and for films cycled over a wide range of scan rates (Fig. 4c). These results indicate that films of electropolymerized PTEBTT are not limited by electronic conductivity or electrolyte diffusion aspects. As illustrated in Figure 4c, the redox peak intensities (anodic, $\mathrm{I}_{\mathrm{pa}}$, and cathodic, $\mathrm{I}_{\mathrm{pc}}$ ) for electrodeposited films of PTEBTT were found to vary linearly with the square root of the scan rate (correlation factors given in inset), consistent with a reversible system. ${ }^{41}$ The interpolations calculated give $\mathrm{I}_{\mathrm{pa}}=-0.13(3) \mathrm{v}^{1 / 2}+$ 2.26(4) and $\mathrm{I}_{\mathrm{pc}}=-0.21(2) \mathrm{v}^{1 / 2}-1.63(3)$ with $\mathrm{v}$ representing the scan rate investigated. 

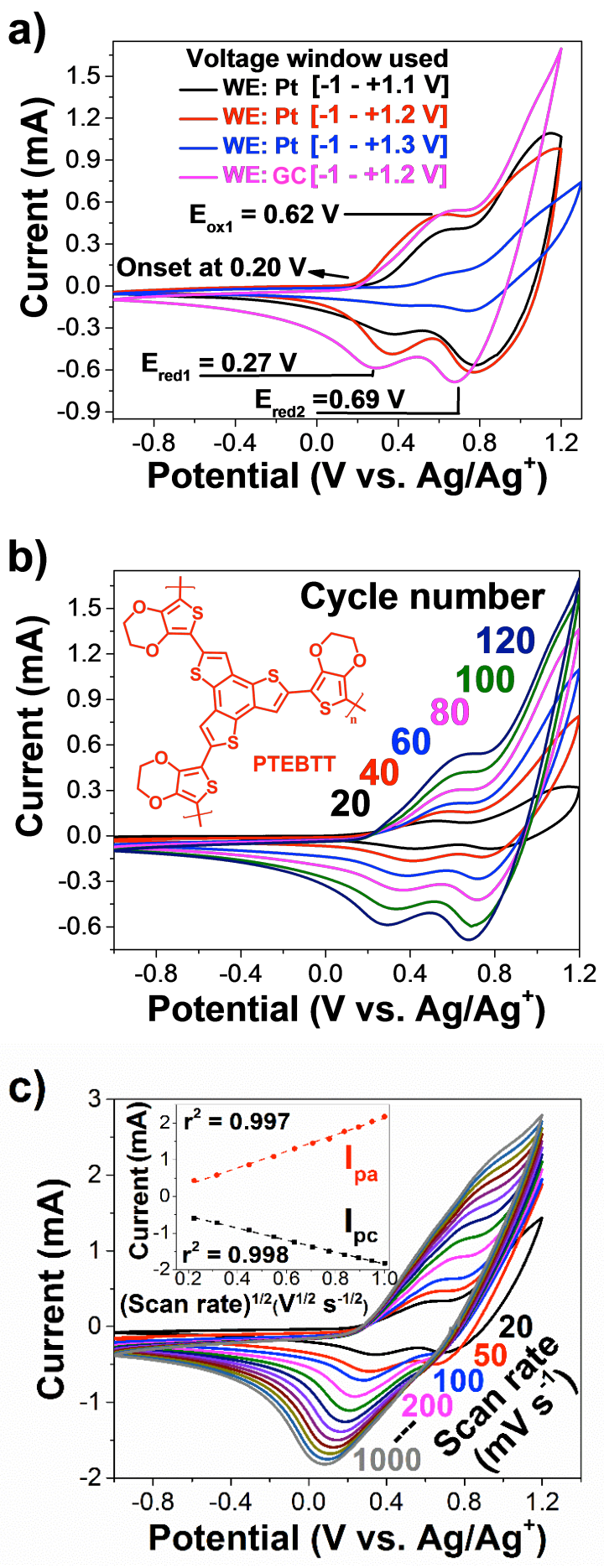

Figure 4 (a) Cyclic voltammograms of PTEBTT films electropolymerized on various working electrodes and voltage windows (collected in ACN). Electrodeposition conditions: $1 \mathrm{mM}$ 
monomer solutions in DCM; 120 deposition cycles; deposition scan rate of $50 \mathrm{mV} \mathrm{s}^{-1}$. (b) Cyclic voltammograms of PTEBTT films on glassy carbon button electrodes as a function of the number of electrodeposition cycles (collected in ACN). Electrodeposition conditions: $1 \mathrm{mM}$ monomer solutions in DCM; 120 deposition cycles in a voltage window of $-1.0-+1.2 \mathrm{~V}$ (vs. $\mathrm{Ag} / \mathrm{Ag}^{+}$); deposition scan rate of $50 \mathrm{mV} \mathrm{s}^{-1}$. (c) Cyclic voltammograms of PTEBTT films on glassy carbon button electrodes as a function of scan rate (collected in ACN). Electrodeposition conditions: $1 \mathrm{mM}$ monomer solutions in DCM; 20 deposition cycles in a voltage window of -1.0 $-+1.2 \mathrm{~V}$ (vs. $\left.\mathrm{Ag} / \mathrm{Ag}^{+}\right)$; deposition scan rate of $50 \mathrm{mV} \mathrm{s}{ }^{-1}$. Inset: anodic $\left(\mathrm{I}_{\mathrm{pa}}\right)$ and cathodic $\left(\mathrm{I}_{\mathrm{pc}}\right)$ current intensity variations of the first redox couple of PTEBTT as a function of the square root of the scan rate.

Table 1 Summary of electrodeposition conditions for PTEBTT, PEDOT, and several TEBTT/EDOT-based copolymers prepared from several solutions of different TEBTT/EDOT monomer compositions (in DCM) and the associated areal capacitance $(\mathrm{Ca})$ values on various working electrodes (WE). Experimental details: deposition scan rate of $50 \mathrm{mV} \mathrm{s}$; all measurements performed in ACN. 


\begin{tabular}{|c|c|c|c|c|c|}
\hline $\begin{array}{c}\text { Monomer } \\
\text { Solution } \\
\text { Composition / } \\
\text { Concentration }\end{array}$ & WE & $\begin{array}{c}\text { Condition of } \\
\text { Electrodeposition }\end{array}$ & $\begin{array}{c}\text { Time/Number } \\
\text { of Deposition } \\
\text { Cycles }\end{array}$ & $\begin{array}{c}C a \\
\left(\mathrm{mF} \mathrm{cm} \mathrm{cm}^{-2}\right)\end{array}$ & $\begin{array}{l}\text { Conditions of } \\
\text { Measurement }\end{array}$ \\
\hline $\begin{array}{c}\text { TEBTT/EDOT } \\
\mathbf{1 : 0} \\
1 \mathrm{mM} \\
\end{array}$ & $\mathrm{Pt}$ & $\begin{array}{l}\text { Potentiostatic } \\
\mathrm{I}=1.2 \mathrm{~V}\end{array}$ & $\begin{array}{l}20 \mathrm{~min} \\
40 \mathrm{~min} \\
50 \mathrm{~min} \\
\end{array}$ & $\begin{array}{l}15.6 \mathrm{mF} \mathrm{cm}^{-2} \\
44.6 \mathrm{mF} \mathrm{cm}^{-2} \\
21.3 \mathrm{mF} \mathrm{cm}^{-2}\end{array}$ & $\begin{array}{c}1 \mathrm{~mA} \mathrm{~cm}-2 \\
\text { between }[0-0.8 \mathrm{~V}]\end{array}$ \\
\hline $\begin{array}{c}\text { TEBTT/EDOT } \\
\mathbf{1 : 0} \\
1 \mathrm{mM} \\
\end{array}$ & $\mathrm{Pt}$ & $\begin{array}{c}\text { Pulsed potentiostatic } \\
\mathrm{I}_{1}=1.2 \mathrm{~V}(1 \mathrm{~s}) \\
\mathrm{I}_{2}=-1.0 \mathrm{~V}(2 \mathrm{~s})\end{array}$ & $\begin{array}{c}600\left(I_{1}-I_{2}\right) \\
1200\left(I_{1}-I_{2}\right) \\
1800\left(I_{1}-I_{2}\right) \\
\end{array}$ & $\begin{array}{l}40.6 \mathrm{mF} \mathrm{cm}^{-2} \\
45.3 \mathrm{mF} \mathrm{cm}^{-2} \\
44.1 \mathrm{mF} \mathrm{cm}^{-2}\end{array}$ & $\begin{array}{c}1 \mathrm{~mA} \mathrm{~cm}-2 \\
\text { between }[0-0.8 \mathrm{~V}]\end{array}$ \\
\hline $\begin{array}{c}\text { TEBTT/EDOT } \\
\mathbf{1 : 0} \\
1 \mathrm{mM} \\
\end{array}$ & $\mathrm{Pt}$ & $\begin{array}{c}\text { Cycling } \\
{[-1-1.1 \mathrm{~V}]}\end{array}$ & $\begin{array}{l}40 \text { cycles } \\
80 \text { cycles } \\
120 \text { cycles }\end{array}$ & $\begin{array}{l}41.6 \mathrm{mF} \mathrm{cm}^{-2} \\
124.0 \mathrm{mF} \mathrm{cm}^{-2} \\
184.5 \mathrm{mF} \mathrm{cm}^{-2}\end{array}$ & $\begin{array}{c}1 \mathrm{~mA} \mathrm{~cm}{ }^{-2} \\
\text { between }[0-0.8 \mathrm{~V}]\end{array}$ \\
\hline $\begin{array}{c}\text { TEBTT/EDOT } \\
\mathbf{1 : 0} \\
1 \mathrm{mM} \\
\end{array}$ & $\mathrm{Pt}$ & $\begin{array}{c}\text { Cycling } \\
{[-1-1.2 \mathrm{~V}]}\end{array}$ & $\begin{array}{l}40 \text { cycles } \\
80 \text { cycles } \\
120 \text { cycles } \\
\end{array}$ & $\begin{array}{c}61.0 \mathrm{mF} \mathrm{cm}^{-2} \\
141.0 \mathrm{mF} \mathrm{cm}^{-2} \\
186.0 \mathrm{mF} \mathrm{cm}^{-2}\end{array}$ & $\begin{array}{c}1 \mathrm{~mA} \mathrm{~cm}{ }^{-2} \\
\text { between }[0-0.7 \mathrm{~V}]\end{array}$ \\
\hline $\begin{array}{c}\text { TEBTT/EDOT } \\
\mathbf{1 : 0} \\
1 \mathrm{mM} \\
\end{array}$ & $\mathrm{Pt}$ & $\begin{array}{c}\text { Cycling } \\
{[-1-1.3 \mathrm{~V}]}\end{array}$ & $\begin{array}{l}40 \text { cycles } \\
80 \text { cycles } \\
120 \text { cycles }\end{array}$ & $\begin{array}{l}20.6 \mathrm{mF} \mathrm{cm}^{-2} \\
55.0 \mathrm{mF} \mathrm{cm}^{-2} \\
17.9 \mathrm{mF} \mathrm{cm}^{-2}\end{array}$ & $\begin{array}{c}1 \mathrm{~mA} \mathrm{~cm}-2 \\
\text { between }[0-0.8 \mathrm{~V}]\end{array}$ \\
\hline $\begin{array}{c}\text { TEBTT/EDOT } \\
\mathbf{1 : 0} \\
1 \mathrm{mM}\end{array}$ & GC & $\begin{array}{c}\text { Cycling } \\
{[-1-1.2 \mathrm{~V}]}\end{array}$ & $\begin{array}{l}40 \text { cycles } \\
80 \text { cycles } \\
120 \text { cycles }\end{array}$ & $\begin{array}{c}29.5 \mathrm{mF} \mathrm{cm}^{-2} \\
99.0 \mathrm{mF} \mathrm{cm}^{-2} \\
271.1 \mathrm{mF} \mathrm{cm}^{-2}\end{array}$ & $\begin{array}{c}1 \mathrm{~mA} \mathrm{~cm}-2 \\
\text { between }[0-0.8 \mathrm{~V}]\end{array}$ \\
\hline $\begin{array}{c}\text { TEBTT/EDOT } \\
\mathbf{3 : 1} \\
1 \mathrm{mM} \\
\end{array}$ & GC & $\begin{array}{c}\text { Cycling } \\
{[-1-1.2 \mathrm{~V}]}\end{array}$ & $\begin{array}{l}40 \text { cycles } \\
80 \text { cycles } \\
120 \text { cycles }\end{array}$ & $\begin{array}{c}53.7 \mathrm{mF} \mathrm{cm}^{-2} \\
193.6 \mathrm{mF} \mathrm{cm}^{-2} \\
323.4 \mathrm{mF} \mathrm{cm}^{-2}\end{array}$ & $\begin{array}{c}1 \mathrm{~mA} \mathrm{~cm}^{-2} \\
\text { between }[-0.2-0.8 \mathrm{~V}]\end{array}$ \\
\hline $\begin{array}{c}\text { TEBTT:EDOT } \\
\mathbf{1 : 1} \\
2.5 \mathrm{mM} \\
\end{array}$ & GC & $\begin{array}{c}\text { Cycling } \\
{[-1-1.2 \mathrm{~V}]}\end{array}$ & $\begin{array}{l}40 \text { cycles } \\
80 \text { cycles } \\
120 \text { cycles } \\
\end{array}$ & $\begin{array}{l}139.0 \mathrm{mF} \mathrm{cm}^{-2} \\
383.8 \mathrm{mF} \mathrm{cm}^{-2} \\
443.8 \mathrm{mF} \mathrm{cm}^{-2}\end{array}$ & $\begin{array}{c}1 \mathrm{~mA} \mathrm{~cm}^{-2} \\
\text { between }[-0.2-0.8 \mathrm{~V}]\end{array}$ \\
\hline $\begin{array}{c}\text { TEBTT:EDOT } \\
\mathbf{1 : 3} \\
5 \mathrm{mM}\end{array}$ & GC & $\begin{array}{c}\text { Cycling } \\
{[-1-1.2 \mathrm{~V}]}\end{array}$ & $\begin{array}{l}40 \text { cycles } \\
80 \text { cycles } \\
120 \text { cycles }\end{array}$ & $\begin{array}{l}99.8 \mathrm{mF} \mathrm{cm}^{-2} \\
127.1 \mathrm{mF} \mathrm{cm}^{-2} \\
356.7 \mathrm{mF} \mathrm{cm}^{-2}\end{array}$ & $\begin{array}{c}1 \mathrm{~mA} \mathrm{~cm}^{-2} \\
\text { between }[-0.2-0.8 \mathrm{~V}]\end{array}$ \\
\hline $\begin{array}{c}\text { TEBTT:EDOT } \\
\mathbf{1 : 9} \\
5 \mathrm{mM} \\
\end{array}$ & GC & $\begin{array}{c}\text { Cycling } \\
{[-1-1.2 \mathrm{~V}]}\end{array}$ & $\begin{array}{l}40 \text { cycles } \\
80 \text { cycles } \\
120 \text { cycles } \\
\end{array}$ & $\begin{array}{c}59.0 \mathrm{mF} \mathrm{cm}^{-2} \\
127.1 \mathrm{mF} \mathrm{cm}^{-2} \\
218.0 \mathrm{mF} \mathrm{cm}^{-2}\end{array}$ & $\begin{array}{c}1 \mathrm{~mA} \mathrm{~cm}^{-2} \\
\text { between }[-0.2-0.8 \mathrm{~V}]\end{array}$ \\
\hline $\begin{array}{c}\text { TEBTT:EDOT } \\
\mathbf{5 : 9 5} \\
5 \mathrm{mM}\end{array}$ & GC & $\begin{array}{c}\text { Cycling } \\
{[-1-1.2 \mathrm{~V}]}\end{array}$ & $\begin{array}{l}40 \text { cycles } \\
80 \text { cycles } \\
120 \text { cycles }\end{array}$ & $\begin{array}{c}57.7 \mathrm{mF} \mathrm{cm}^{-2} \\
125.7 \mathrm{mF} \mathrm{cm}^{-2} \\
189.3 \mathrm{mF} \mathrm{cm}^{-2}\end{array}$ & $\begin{array}{c}1 \mathrm{~mA} \mathrm{~cm}^{-2} \\
\text { between }[-0.2-0.8 \mathrm{~V}]\end{array}$ \\
\hline $\begin{array}{c}\text { TEBTT:EDOT } \\
\mathbf{0 : 1} \\
5 \mathrm{mM} \\
\end{array}$ & $\mathrm{GC}$ & $\begin{array}{c}\text { Cycling } \\
{[-1-1.2 \mathrm{~V}]}\end{array}$ & $\begin{array}{l}40 \text { cycles } \\
80 \text { cycles } \\
120 \text { cycles }\end{array}$ & $\begin{array}{l}24.0 \mathrm{mF} \mathrm{cm}^{-2} \\
40.3 \mathrm{mF} \mathrm{cm}^{-2} \\
55.9 \mathrm{mF} \mathrm{cm}^{-2}\end{array}$ & $\begin{array}{c}1 \mathrm{~mA} \mathrm{~cm}^{-2} \\
\text { between }[-0.2-0.8 \mathrm{~V}]\end{array}$ \\
\hline $\begin{array}{c}\text { TEBTT:EDOT } \\
\mathbf{0 : 1} \\
1 \mathrm{mM} \\
\end{array}$ & GC & $\begin{array}{c}\text { Cycling } \\
{[-1-1.2 \mathrm{~V}]}\end{array}$ & 120 cycles & $12.1 \mathrm{mF} \mathrm{cm}^{-2}$ & $\begin{array}{c}1 \mathrm{~mA} \mathrm{~cm}^{-2} \\
\text { between }[0.1-0.8 \mathrm{~V}]\end{array}$ \\
\hline
\end{tabular}

Pt: platinum button electrode; GC: glassy carbon electrode. 

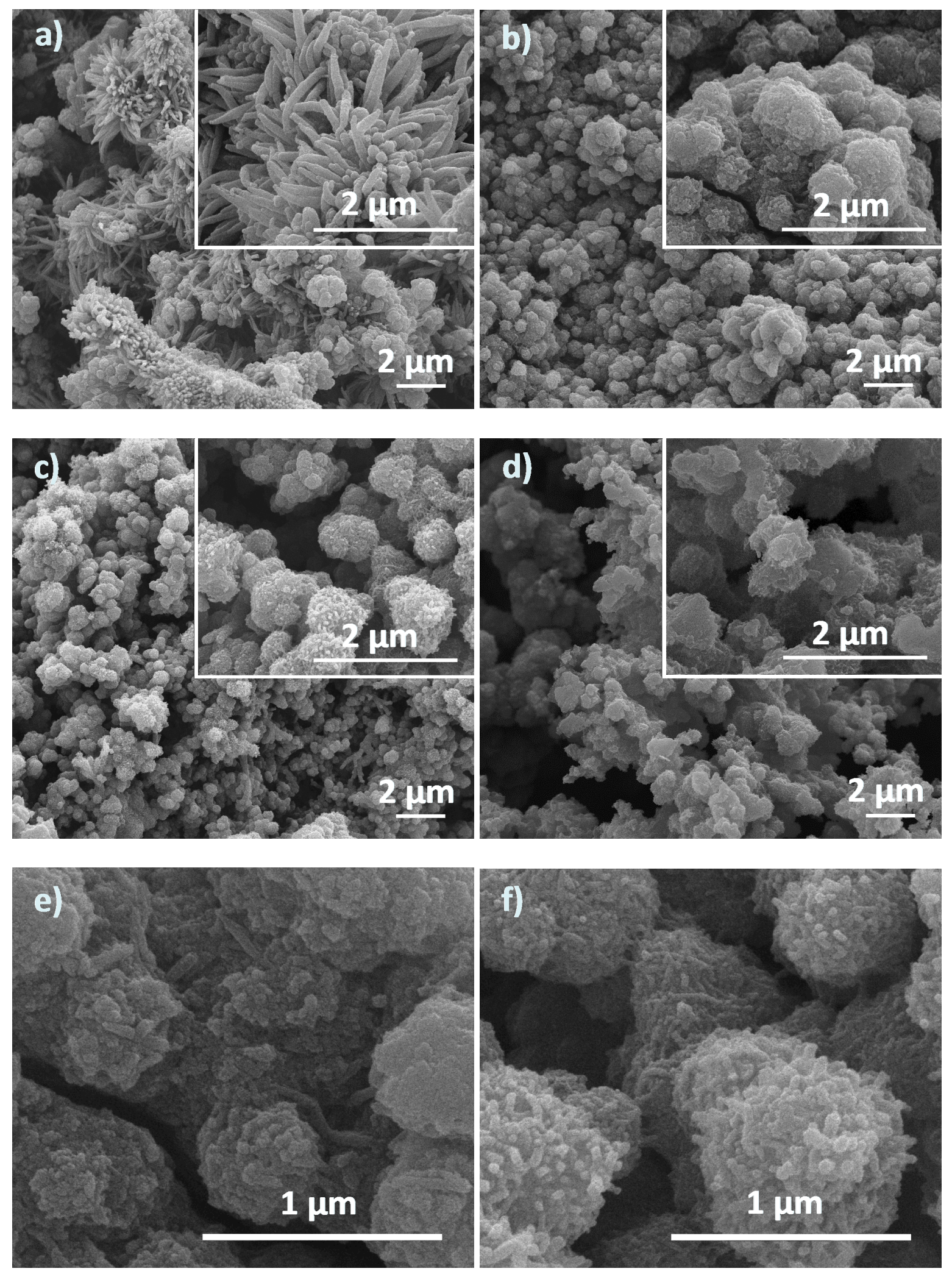
Figure 5 SEM images of the morphologies of electrodeposited polymer films prepared from several monomer solutions of different TEBTT/EDOT monomer compositions: (a) 1:0, (b, e) 1:1, (c, f) 1:9, and (d) 0:1. Electrodeposition conditions: $1 \mathrm{mM}$ monomer solutions in DCM; 120 deposition cycles in a voltage window of $-1.0-+1.2 \mathrm{~V}\left(\mathrm{vs} . \mathrm{Ag} / \mathrm{Ag}^{+}\right.$), on glassy carbon button electrodes; deposition scan rate of $50 \mathrm{mV} \mathrm{s}^{-1}$.

Following the conditions of electropolymerization employed earlier in ACN, now applied in DCM, films of electrodeposited PEDOT yield lower $C a$ values (Table 1) than those obtained earlier from ACN: PEDOT electrodeposited on carbon cloth from $1 \mathrm{mM}$ and $5 \mathrm{mM}$ monomer solutions yield capacitance values of $c a .12 \mathrm{mF} \mathrm{cm}^{-2}$ and $c a .55 \mathrm{mF} \mathrm{cm}$ (at $1 \mathrm{~mA} \mathrm{~cm}^{-2}$ ), respectively (Table 1). These lower $C a$ values may result from the lower propensity of the monomer to undergo electropolymerization in the lower dielectric constant solvent DCM $(\varepsilon=$ $8.9)^{42}(\mathrm{ACN}: \varepsilon=36.6),{ }^{42}$ combined with the effect of using a WE that is inherently less porous (on going from carbon cloth to the GC button electrode) ${ }^{43,44}$ The SEM image in Figure $5 \mathrm{~d}$ shows aggregate patterns in a relatively wide size distribution $(650-1,000 \mathrm{~nm})$ spread across films that are several micrometers thick.

Next, we prepared P(TEBTT/EDOT) by electrodepostion from several solutions of different TEBTT/EDOT monomer compositions; electrodeposition conditions: $1 \mathrm{mM}$ monomer solutions in dichloromethane (DCM); 120 deposition cycles in a voltage window of $-1.0-+1.2 \mathrm{~V}$ (vs. $\mathrm{Ag} / \mathrm{Ag}^{+}$), on glassy carbon (GC) button electrodes; deposition scan rate of $50 \mathrm{mV} \mathrm{s}$. As depicted by the SEM images shown in Figures 5b and 5c, the P(TEBTT/EDOT)-based framework exhibit morphologies that are fairly distinct from those of their homopolymer counterparts, PTEBTT and PEDOT. In particular, the higher-magnification SEM images shown in Figures 5e and $5 f$ indicate that the aggregate patterns formed are highly nanostructured (Fig. $5 \mathrm{~b}$ and $5 \mathrm{e}, 1: 1$ ratio in 
TEBTT/EDOT, aggregates: $<100 \mathrm{~nm}$; clusters: 500-1,200 nm; Fig. 5c and 5f, 1:9 ratio in TEBTT/EDOT, aggregates: $<50 \mathrm{~nm}$; clusters: $600-1,000 \mathrm{~nm}$ ). Here, we note that the dense, highly textured hierarchical networks formed by P(TEBTT/EDOT) are consistent with the values of high areal capacitance given in Table 1 . The CV curves of the electrodeposited $\mathrm{P}($ TEBTT/EDOT) shown in Figure 6a reflect inherently more capacitive material systems compared to their homopolymer counterparts, PTEBTT or PEDOT; observations consistent with the higher $\mathrm{Ca}$ values obtained for the copolymers and summarized in Table 1, reaching up to $443.8 \mathrm{mF} \mathrm{cm}^{-2}$ (at $\left.1 \mathrm{~mA} \mathrm{~cm}^{-2}\right)(1: 1$ ratio in TEBTT/EDOT). In particular, copolymers that result from the addition of only 5 mol.\% of TEBTT in the initial TEBTT/EDOT monomer solution exhibit significantly higher $C a$ values compared to PEDOT: $189 \mathrm{mF} \mathrm{cm}^{-2}$ vs. $12 \mathrm{mF} \mathrm{cm}^{-2}$ (at 1 $\mathrm{mA} \mathrm{cm} \mathrm{cm}^{-2}$ ), respectively, representing a ca. 15-fold capacitance increase. These results suggest that TEBTT motifs play a critical role in the development of open, hierarchical morphologies required to maximize areal capacitances and promote electrolyte diffusion in conventional electropolymerized $\pi$-conjugated systems such as PEDOT. Figure 6 also shows how the capacitive cycles of the several TEBTT/EDOT-based copolymers electrodeposited and characterized by CV reflect redox behaviors that are not intermediate between those of PTEBTT and PEDOT - an observation that points to a random integration of TEBTT and EDOT monomers during the electropolymerization step.

Figures $6 \mathrm{~b}$ and $6 \mathrm{c}$ depict the areal capacitance of PTEBTT, PEDOT, and the TEBTT/EDOTbased copolymers obtained from the electropolymerization of several TEBTT/EDOT monomer compositions (3:1, 1:1, 1:3, and 1:9 ratios) as a function of current density (Fig. 6b) and cycle number (Fig. 6c). It is interesting to note that several TEBTT/EDOT-based copolymers $(1: 1$, 1:3, and 1:9 ratios) undergo only little capacitance variations with current density increments, 
suggesting excellent electrolyte diffusion within the highly porous P(TEBTT/EDOT)-based frameworks. Figure 6c shows that films of electrodeposited PTEBTT are relatively resilient to repeated electrochemical cycling with $c a .73 \%$ of capacitance retained (at $2 \mathrm{~mA} \mathrm{~cm}{ }^{-2}$ ) over 1,000 cycles (vs. 96\% for PEDOT over 1,000 cycles (at $2 \mathrm{~mA} \mathrm{~cm}^{-2}$ ). Here, we note that our estimate of the stability of the homopolymer PTEBTT is on the low end of the capacitance retention reported in prior work (ca. $95 \%$ over 1,400 cycles), ${ }^{30}$ a difference that is likely to stem from the significantly thicker films examined in this study: PTEBTT is electrodeposited in 120 cycles between -1.0 and $+1.2 \mathrm{~V}$ vs. only 8 cycles between 0.0 and $+1.0 \mathrm{~V}$ in earlier work. ${ }^{30}$ Likewise, $^{2}$ all of the TEBTT/EDOT-based copolymers show $>70 \%$ of capacitance retention (at $2 \mathrm{~mA} \mathrm{~cm}^{-2}$ ) over 1,000 cycles (with up to ca. $89 \%$ achieved), demonstrating satisfying long-term stability upon repeated electrochemical cycling. These stability figures, ranging between those of PTEBTT and PEDOT, are greater than those reported for some of the more conventional conjugated polymers such as $50 \%$ capacitance retention over 1,000 cycles (at $2 \mathrm{~mA} \mathrm{~cm}$ ) for polypyrrole, ${ }^{9} 84 \%$ capacitance retention after 200 cycles for poly(3-methylthiophene) (longer cycling times not provided), and 70\% capacitance retention after 1,000 cycles for PANI. ${ }^{5,9}$ Last, we note that the mechanical stability and long-term cycling performances of the P(TEBTT/EDOT)-based frameworks may be further improved in hybrid carbon-based composite systems including carbon nanotubes or graphene oxide; however this falls beyond the scope of this report..$^{10}$ 

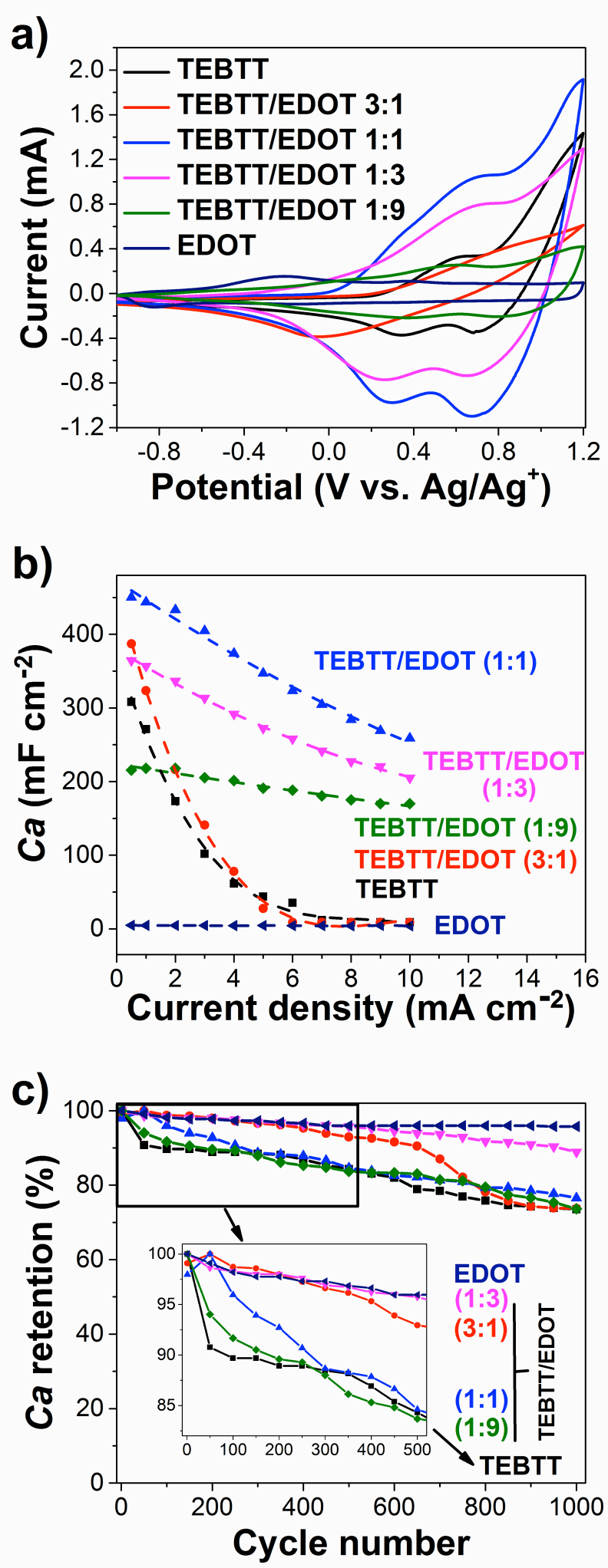

Figure 6 (a) Cyclic voltammograms of electrodeposited PTEBTT, PEDOT, and several TEBTT/EDOT-based copolymers prepared from several solutions of different TEBTT/EDOT 
monomer compositions: 1:0 (black), 3:1 (red), 1:1 (blue), 1:3 (magenta), 1:9 (green), and 0:1 (dark blue); curves collected at a scan rate of $20 \mathrm{mV} \mathrm{s}^{-1}$. Electrodeposition conditions: $1 \mathrm{mM}$ monomer solutions in DCM; 120 deposition cycles in a voltage window of $-1.0-+1.2 \mathrm{~V}$ (vs. $\mathrm{Ag} / \mathrm{Ag}^{+}$), on glassy carbon button electrodes; deposition scan rate of $50 \mathrm{mV} \mathrm{s}^{-1}$. (b) areal capacitance vs. current density increments for several TEBTT/EDOT-based copolymers. (c) areal capacitance vs. cycle number for several TEBTT/EDOT-based copolymers (at $2 \mathrm{~mA} \mathrm{~cm}^{-2}$ ).

\section{CONCLUSION}

In summary, we have shown that high-surface-area $\pi$-conjugated polymeric networks can be synthesized via the electrochemical copolymerization of the $2 \mathrm{D}$ (trivalent) motifs benzo[1,2$\left.b: 3,4-b^{\prime}: 5,6-b^{\prime \prime}\right]$ trithiophene (BTT) and tris(ethylenedioxythiophene)benzo[1,2-b:3,4- $b$ ':5,6$b$ '] trithiophene (TEBTT) with EDOT. Of all the material systems studied, P(TEBTT/EDOT)based frameworks achieved the highest areal capacitance with values as high as $443.8 \mathrm{mF} \mathrm{cm}^{-2}$ (at $1 \mathrm{~mA} \mathrm{~cm}$ ), higher than those achieved by the respective homopolymers (PTEBTT and PEDOT) in the same experimental conditions of electrodeposition (PTEBTT: $271.1 \mathrm{mF} \mathrm{cm}^{-2}$ (at $1 \mathrm{~mA} \mathrm{~cm}^{-2}$ ); PEDOT: $12.1 \mathrm{mF} \mathrm{cm}^{-2}$ (at $1 \mathrm{~mA} \mathrm{~cm}^{-2}$ ). The high areal capacitance achieved with $\mathrm{P}($ TEBTT/EDOT - with up to $c a$. 30-fold capacitance increases compared to PEDOT - can be related to the open, highly porous hierarchical $\pi$-conjugated frameworks formed during the electropolymerization. We find that both PTEBTT- and P(TEBTT/EDOT)-based frameworks are resilient to repeated electrochemical cycling, maintaining $>70 \%$ capacitance over 1,000 cycles (up to $89 \%$ achieved), making them promising systems for high life cycle capacitive electrode applications. Lastly, the use of 2D motifs such as TEBTT in the synthesis of electropolymerized hierarchical $\pi$-conjugated frameworks with particularly high areal 
capacitance may be applicable to other established capacitive polymeric systems such as polythiophenes, polypyrrole, and PANI.

\title{
ASSOCIATED CONTENT
}

Supporting Information. Detailed syntheses of BTT and TEBTT with their respective ${ }^{1} \mathrm{H}$ and ${ }^{13} \mathrm{C}$ NMR spectra. This material is available free of charge via the Internet at http://pubs.acs.org.

\section{AUTHOR INFORMATION \\ Corresponding Author \\ * Address correspondence to pierre.beaujuge@kaust.edu.sa}

\author{
Author Contributions \\ ${ }^{\perp}$ These authors contributed equally (A.R. and A.L.). All authors contributed to the writing of
} this manuscript. All authors have given approval to the final version of the manuscript.

\section{ACKNOWLEDGMENT}

The authors acknowledge the financial support of the Office of Competitive Research Funds (OCRF) at King Abdullah University of Science and Technology (KAUST) under the "Competitive Research Grant" (CRG) program No. URF/1/1399. The authors thank the Advanced Imaging and Characterization Laboratories at KAUST for technical support.

\section{REFERENCES}

(1) Mike, J. F.; Lutkenhaus, J. L., Recent Advances in Conjugated Polymer Energy Storage. J. Polym. Sci., Part B: Polym. Phys. 2013, 51 (7), 468-480. 
(2) Simon, P.; Gogotsi, Y., Materials for Electrochemical Capacitors. Nat. Mater. 2008, 7 (11), 845-854.

(3) Yu, G.; Xie, X.; Pan, L.; Bao, Z.; Cui, Y., Hybrid Nanostructured Materials for HighPerformance Electrochemical Capacitors. Nano Energy 2013, 2 (2), 213-234.

(4) Nyholm, L.; Nyström, G.; Mihranyan, A.; Strømme, M., Toward Flexible Polymer and Paper-Based Energy Storage Devices. Adv. Mater. 2011, 23 (33), 3751-3769.

(5) Snook, G. A.; Kao, P.; Best, A. S., Conducting-Polymer-Based Supercapacitor Devices and Electrodes. J. Power Sources 2011, 196 (1), 1-12.

(6) Chen, S.; Xing, W.; Duan, J.; Hu, X.; Qiao, S. Z., Nanostructured Morphology Control for Efficient Supercapacitor Electrodes. J. Mater. Chem. A 2013, 1 (9), 2941-2954.

(7) Demarconnay, L.; Raymundo-Piñero, E.; Béguin, F., A Symmetric Carbon/Carbon

Supercapacitor Operating at $1.6 \mathrm{~V}$ by Using a Neutral Aqueous Solution. Electrochem. Commun . 2010, 12 (10), 1275-1278.

(8) Wang, K.; Wu, H.; Meng, Y.; Wei, Z., Conducting Polymer Nanowire Arrays for High Performance Supercapacitors. Small 2014, 10 (1), 14-31.

(9) Wang, G.; Zhang, L.; Zhang, J., A Review of Electrode Materials for Electrochemical Supercapacitors. Chem. Soc. Rev. 2012, 41 (2), 797-828.

(10) Yan, J.; Wang, Q.; Wei, T.; Fan, Z., Recent Advances in Design and Fabrication of Electrochemical Supercapacitors with High Energy Densities. Adv. Energy Mater. 2014, 4 (4), 1300816-1300816.

(11) Roncali, J., Synthesis and Properties of Polythiophenes. In Conductive Electroactive Polymers, CRC Press: 2008, pp 197-230.

(12) Wang, X.; Sjöberg-Eerola, P.; Eriksson, J.-E.; Bobacka, J.; Bergelin, M., The Effect of Counter Ions and Substrate Material on the Growth and Morphology of Poly(3,4-

Ethylenedioxythiophene) Films: Towards the Application of Enzyme Electrode Construction in Biofuel Cells. Synth. Met. 2010, 160 (13-14), 1373-1381.

(13) Cheng, Q.; Tang, J.; Ma, J.; Zhang, H.; Shinya, N.; Qin, L.-C., Polyaniline-Coated ElectroEtched Carbon Fiber Cloth Electrodes for Supercapacitors. J. Phys. Chem. C 2011, 115 (47), 23584-23590.

(14) Liu, T.; Finn, L.; Yu, M.; Wang, H.; Zhai, T.; Lu, X.; Tong, Y.; Li, Y., Polyaniline and Polypyrrole Pseudocapacitor Electrodes with Excellent Cycling Stability. Nano Lett. 2014, 14 (5), 2522-2527.

(15) Bora, C.; Sharma, J.; Dolui, S., Polypyrrole/Sulfonated Graphene Composite as Electrode Material for Supercapacitor. J. Phys. Chem. C 2014, 118 (51), 29688-29694.

(16) Zhang, H.; Hu, L.; Tu, J.; Jiao, S., Electrochemically Assembling of Polythiophene Film in Ionic Liquids (Ils) Microemulsions and Its Application in an Electrochemical Capacitor.

Electrochim. Acta 2014, 120 (0), 122-127.

(17) D’Arcy, J. M.; El-Kady, M. F.; Khine, P. P.; Zhang, L.; Lee, S. H.; Davis, N. R.; Liu, D. S.; Yeung, M. T.; Kim, S. Y.; Turner, C. L.; Lech, A. T.; Hammond, P. T.; Kaner, R. B., VaporPhase Polymerization of Nanofibrillar Poly(3,4-Ethylenedioxythiophene) for Supercapacitors. ACS Nano 2014, 8 (2), 1500-1510.

(18) Pandey, G. P.; Rastogi, A. C.; Westgate, C. R., All-Solid-State Supercapacitors with Poly(3,4-Ethylenedioxythiophene)-Coated Carbon Fiber Paper Electrodes and Ionic Liquid Gel Polymer Electrolyte. J. Power Sources 2014, 245 (0), 857-865. 
(19) Park, H.-W.; Kim, T.; Huh, J.; Kang, M.; Lee, J. E.; Yoon, H., Anisotropic Growth Control of Polyaniline Nanostructures and Their Morphology-Dependent Electrochemical

Characteristics. ACS Nano 2012, 6 (9), 7624-7633.

(20) Cooper, A. I., Conjugated Microporous Polymers. Adv. Mater. 2009, 21 (12), 1291-1295.

(21) Xu, Y.; Jin, S.; Xu, H.; Nagai, A.; Jiang, D., Conjugated Microporous Polymers: Design, Synthesis and Application. Chem. Soc. Rev. 2013, 42 (20), 8012-8031.

(22) Cherioux, F.; Guyard, L., Synthesis and Electrochemical Properties of Novel 1,3,5-

Tris(Oligothienyl)Benzenes: A New Generation of 3d Reticulating Agents. Adv. Funct. Mater. 2001, 11 (4), 305-309.

(23) Ponomarenko, S. A.; Tatarinova, E. A.; Muzafarov, A. M.; Kirchmeyer, S.; Brassat, L.;

Mourran, A.; Moeller, M.; Setayesh, S.; de Leeuw, D., Star-Shaped Oligothiophenes for

Solution-Processible Organic Electronics: Flexible Aliphatic Spacers Approach. Chem. Mater.

2006, 18 (17), 4101-4108.

(24) Chahma, M. h.; Gilroy, J. B.; Hicks, R. G., Linear and Branched Electroactive Polymers

Based on Ethylenedioxythiophene-Triarylamine Conjugates. J. Mater. Chem. 2007, 17 (45), 4768-4771.

(25) Kearns, J. T.; Roberts, M. E., Enhanced Performance of Triarylamine Redox Electrodes through Directed Electrochemical Polymerization. J. Mater. Chem. 2012, 22 (6), 2392-2394.

(26) Kearns, J. T.; Roberts, M. E., Synthesis of High-Charge Capacity Triarylamine-Thiophene Redox Electrodes Using Electrochemical Copolymerization. J. Mater. Chem. 2012, 22 (48), 25447-25452.

(27) Roberts, M. E.; Wheeler, D. R.; McKenzie, B. B.; Bunker, B. C., High Specific Capacitance Conducting Polymer Supercapacitor Electrodes Based on Poly(Tris(Thiophenylphenyl)Amine). J. Mater. Chem. 2009, 19 (38), 6977-6979.

(28) Kashiki, T.; Kohara, M.; Osaka, I.; Miyazaki, E.; Takimiya, K., Synthesis and Characterization of Benzo[1,2-b:3,4-b:5,6-b]Trithiophene (Btt) Oligomers. J. Org. Chem. 2011, 76 (10), 4061-4070.

(29) Nicolas, Y.; Blanchard, P.; Levillain, E.; Allain, M.; Mercier, N.; Roncali, J., Planarized Star-Shaped Oligothiophenes with Enhanced П-Electron Delocalization. Org. Lett. 2004, 6 (2), 273-276.

(30) Taerum, T.; Lukoyanova, O.; Wylie, R. G.; Perepichka, D. F., Synthesis, Polymerization, and Unusual Properties of New Star-Shaped Thiophene Oligomers. Org. Lett. 2009, 11 (15), 3230-3233.

(31) Chen, G. Z., Understanding Supercapacitors Based on Nano-Hybrid Materials with Interfacial Conjugation. Prog. Nat. Sci.: Mater. Int. 2013, 23 (3), 245-255.

(32) Bäuerle, P.; Götz, G.; Synowczyk, A.; Heinze, J., Donor-Substituted Oligothiophenes, 1 Synthesis and Properties of a Series of Methylthio Oligothiophenes. Liebigs Annalen 1996, 1996 (2), 279-284.

(33) Götz, G.; Scheib, S.; Klose, R.; Heinze, J.; Bäuerle, P., Synthesis and Properties of a Series of Regioregularly Amino-Substituted Oligo- and Polythiophenes. Adv. Funct. Mater. 2002, 12 (10), 723-728.

(34) Audebert, P.; Hapiot, P., Fast Electrochemical Studies of the Polymerization Mechanisms of Pyrroles and Thiophenes. Identification of the First Steps. Existence of Pi-Dimers in Solution. Synth. Met. 1995, 75 (2), 95-102.

(35) Anothumakkool, B.; Torris A. T, A.; Bhange, S. N.; Badiger, M. V.; Kurungot, S., Electrodeposited Polyethylenedioxythiophene with Infiltrated Gel Electrolyte Interface: A Close 
Contest of an All-Solid-State Supercapacitor with Its Liquid-State Counterpart. Nanoscale 2014, $6(11), 5944-5952$.

(36) Ertas, M.; Walczak, R. M.; Das, R. K.; Rinzler, A. G.; Reynolds, J. R., Supercapacitors Based on Polymeric Dioxypyrroles and Single Walled Carbon Nanotubes. Chem. Mater. 2012, 24 (3), 433-443.

(37) Estrada, L. A.; Liu, D. Y.; Salazar, D. H.; Dyer, A. L.; Reynolds, J. R., Poly[Bis-EdotIsoindigo]: An Electroactive Polymer Applied to Electrochemical Supercapacitors.

Macromolecules 2012, 45 (20), 8211-8220.

(38) Zhou, H.; Han, G.; Xiao, Y.; Chang, Y.; Zhai, H.-J., Facile Preparation of Polypyrrole/Graphene Oxide Nanocomposites with Large Areal Capacitance Using Electrochemical Codeposition For supercapacitors. J. Power Sources 2014, 263 (0), 259-267. (39) Groenendaal, L.; Zotti, G.; Aubert, P. H.; Waybright, S. M.; Reynolds, J. R., Electrochemistry of Poly(3,4-Alkylenedioxythiophene) Derivatives. Adv. Mater. 2003, 15 (11), 855-879.

(40) Rodríguez-Calero, G. G.; Lowe, M. A.; Kiya, Y.; Abruña, H. D., Electrochemical and Computational Studies on the Electrocatalytic Effect of Conducting Polymers toward the Redox Reactions of Thiadiazole-Based Thiolate Compounds. J. Phys. Chem. C 2010, 114 (13), 61696176.

(41) Baur, J. E., 19 - Diffusion Coefficients. In Handbook of Electrochemistry, Zoski, C. G., Ed. Elsevier: Amsterdam, 2007, pp 829-848.

(42) Creager, S., 3 - Solvents and Supporting Electrolytes. In Handbook of Electrochemistry, Zoski, C. G., Ed. Elsevier: Amsterdam, 2007, pp 57-IV.

(43) Givehchi, M.; Tardi, M.; Polton, A.; Sigwalt, P., Influence of Monomer Concentration and Dielectric Constant on Transfer Reactions in the Carbocationic Polymerization of Indene. Macromolecules 2000, 33 (3), 710-716.

(44) Matyjaszewski, K.; Lin, C.-H.; Bon, A.; Xiang, J. S., Salt and Solvent Effects in "Living" Carbocationic Polymerization. Macromol. Symp. 1994, 85 (1), 65-78. 


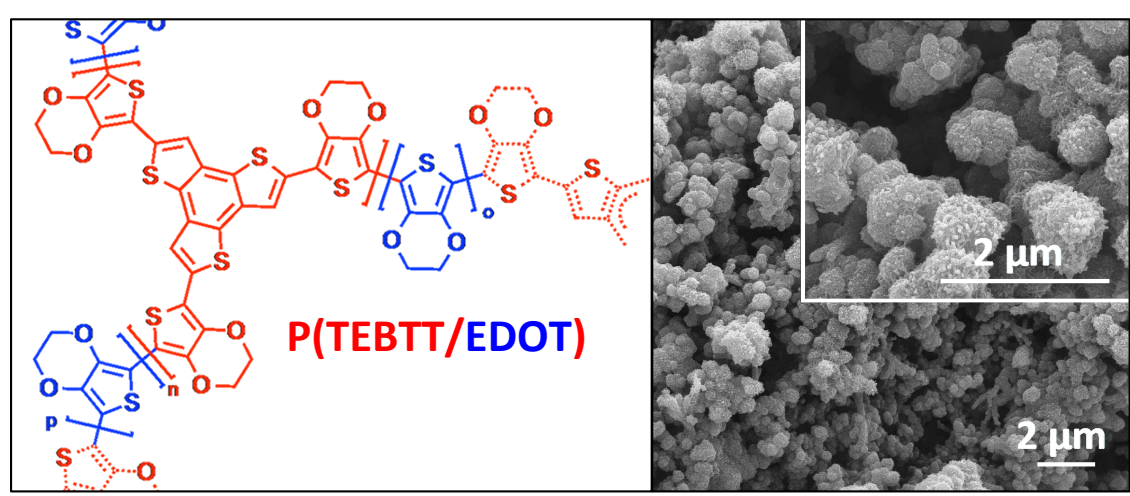

